\title{
Study on mechanical properties of cement mortar with different amount of coal gangue and activator $\mathrm{Na}_{2} \mathrm{SO}_{4}$
}

\author{
Bingke Qin ${ }^{1,2, a}$, Yonghua Ji, ${ }^{1, b}$, Zhiling Bai ${ }^{1, c}$, Qingkao Zhao ${ }^{1, d}$ \\ ${ }^{1}$ School of Chemistry and materials Engineering, Liupanshui Normal University, Liupanshui, China \\ ${ }^{2}$ College of Materials and Metallurgy, Guizhou University, Guiyang, China \\ aquinbingke@126.coml, bhaizhigong@126.com, czhilingbai@126.com, dkr2012@126.com
}

\begin{abstract}
Keywords: Coal gangue; Activation; Chemical activator; mechanical property
Abstract. The phase and composition of Liupanshui coal gangue were determined by XRD and XRF analysis. The coal gangue is calcined at $600^{\circ} \mathrm{C}$ for $2 \mathrm{~h}$, grind $200 \mathrm{mesh}$, and the optimum amount of coal gangue is determined by testing cement mortar with different proportions and testing its compressive and flexural mechanical properties. Under the optimum dosage of coal gangue, the chemical activator $\mathrm{Na}_{2} \mathrm{SO}_{4}$ is added to cement mortar in different proportion to study its influence on the mechanical properties of cement mortar. The results show that the proper amount of coal gangue has little effect on the mechanical properties of cement mortar. When the addition amount is more than $70 \%$, the compressive strength of cement mortar will be reduced remarkably. The optimum amount of coal gangue is $50 \%$, and its compressive strength can reach $23.31 \mathrm{MPa}$ in 28 days. As the chemical activator $\mathrm{Na}_{2} \mathrm{SO}_{4}$ is added. The optimum addition amount of $\mathrm{Na}_{2} \mathrm{SO}_{4}$ was $3 \%$, then compressive strength of specimens $3 \mathrm{~d}$ and $28 \mathrm{~d}$ reached $11.23 \mathrm{MPa}$ and 23.59MPa respectively.
\end{abstract}

\section{Introduction}

One of the wastes produced in the process of coal washing is coal gangue. The stacking of coal gangue will become a waste rock hill and take up a lot of land. When the coal gangue temperature is high in summer, it is prone to spontaneous combustion. After the spontaneous combustion, a large amount of waste gas is produced, which causes serious pollution to the atmosphere[1-3]. The coal gangue by rainfall dripping wet and heavy metal ions will exudation in the local soil and water resources pollution. After the pollution of coal gangue to the environment, it will affect the healthy development of the ecological environment for a long time. Therefore, it has become one of the most important directions of coal solid waste research that how to reuse coal gangue to reuse resources. Liupanshui area is one of the largest coal resources bases in South China. The gangue is discharged millions of tons every year. The massive accumulation of coal gangue has become one of the most urgent problems to be solved in the development of local green health.

Coal gangue should be used in cement cementing material, which is one of its ways of resource utilization. Coal gangue should be activated before use; otherwise it will have bad influence on the performance of cement cementing material. There are many methods for coal gangue activation, mainly including three kinds of mechanical activation, thermal activation and chemical activation, among which thermal activation and chemical activation are often used. Chemical activation is the addition of chemical activators to coal gangue to stimulate the cementitious properties of coal gangue, thus partially replacing cement as a cementitious admixture[4-5]. Liupanshui area of coal gangue composition and physicochemical properties were different greatly, so Liupanshui mining area of coal gangue used in cement cementing materials, first need to reasonable sorting, sorting after coal gangue and resource utilization, maximize the use of local coal gangue, coal gangue has guiding significance to solve the pollution of the region and application the problem.

\section{Experiment}

Cement with ordinary Portland cement on the local market, the mark of P.O32.5 cement; Sand as local stone sand $5 \mathrm{~mm}$, mud content is less than $0.5 \%$. Coal gangue comes from Laoyingshan mine in 
Liupanshui. The fly ash is adopted by Wangjiazhai Yanma power plant. Polycarboxylate water reducer is used in water reducing agent. The purity of activator $\mathrm{Na}_{2} \mathrm{SO}_{4}$ is $99.9 \%$. Water is placed more than $24 \mathrm{~h}$ of tap water.

TD-2500 phase X-ray multi crystal diffractometer and ARL9900XP + X ray fluorescence spectrometer were used to detect the phase composition of coal gangue respectively. Coal gangue after self medium separator separates the poor mechanical property of coal gangue, better mechanical property of coal gangue after washing the precipitate after drying and poor mechanical properties of coal gangue in XL-1 furnace in calcination, and the calcination temperature of $600^{\circ} \mathrm{C}$, the calcined coal gangue through ball milling, grinding fineness is less than the 200 purpose powder, according to a certain proportion of cement cementitious materials. The water reducing agent is added into cement mortar according to the percentage of cement and gangue.

Try to measure the strength, through excitation of coal gangue in different dosage (mass fraction) mixed into cement mortar, and according to GB/T 17617 - 1999 "cement mortar strength test method (ISO method)" for molding and curing specimens using WAW-600C type universal testing machine, test of cement the mechanical properties of the specimen sand.

\section{Results and discussion}

Composition and phase analysis of coal gangue. Table 1 is the XRF test result of raw coal gangue. The results show that the main components of coal gangue are silicon oxides and iron and aluminum oxides, and the proportion of these three accounts for nearly $80 \%$ of the total coal gangue content. In addition, the coal gangue in Liupanshui also contains a certain amount of titanium.

Table.1 Analysis of main elements of coal gangue by XRF

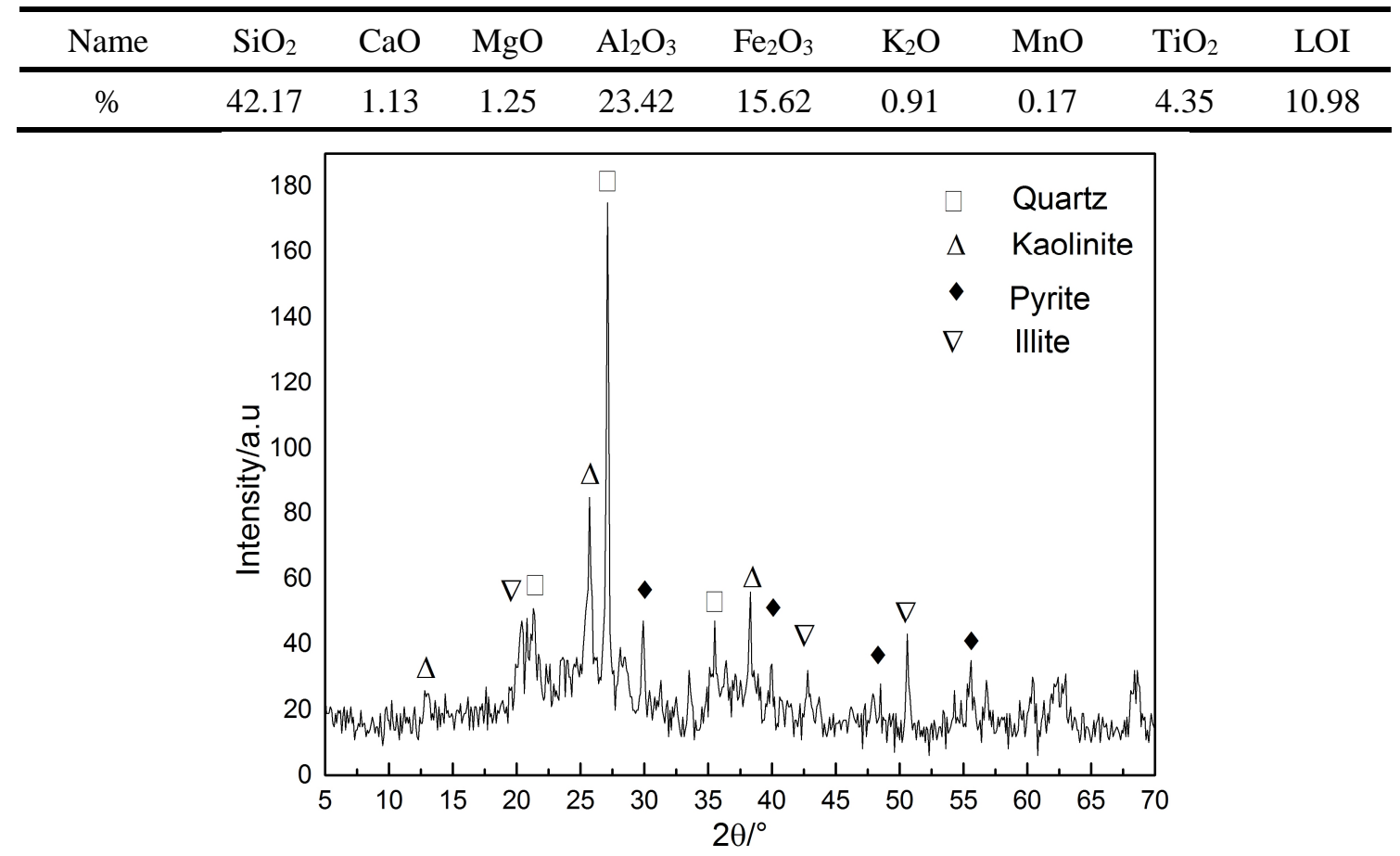

Fig.1 XRD patterns of raw coal gangue powder

Figure. 1 is the XRD patterns of coal gangue. The phase analysis shows that the main components of coal gangue are quartz, kaolinite, and a small amount of illite and pyrite and some organic matters. Gangue at high temperature will make kaolinite, pyrite and organic matter decomposition, thereby changing the original mineral composition of coal gangue, and improve the activity of coal gangue.

Effect of coal gangue content on mechanical properties of cement mortar. The kaolinite in coal gangue occurs at about $500^{\circ} \mathrm{C}$ and occurs when the hydroxyl groups are dehydrated and then transformed into amorphous met kaolin. In the stage of $500 \sim 744.4^{\circ} \mathrm{C}$, the oxidation exothermic reaction of organic matter occurs, the oxidation exothermic reaction of pyrite, and the decomposition 
endothermic reaction of kaolinite [4]. According to the literature report and the experimental study of the activation temperature at first stage, the calcination temperature of coal gangue is determined to be 600 degrees centigrade.

When the ratio of water to cement is 0.32 , the content of fly ash is $15 \%$, and the content of polycarboxylate water reducer is $1 \%$, the influence of different amount of gangue on the mechanical properties of cement mortar is investigated. The results of experimental compressive strength and flexural strength are shown in Table 2 and table 3, respectively. Can be seen from table 2, with the coal gangue cement increased, the compressive strength of cement mortar with coal gangue in different period decreased, coal gangue added quantity exceeds $70 \%$, the compressive strength of the samples especially early compressive strength decreased rapidly, when the content is $110 \%$, the compressive strength of 3 days is almost zero. Coal gangue content is lower than $70 \%$, while the early compressive strength of specimens decreased, but the late strength gradually increased. This is consistent with the reports that the thermal activation of coal gangue contributes to the later strength of cement cementitious materials [6].

Table 2. Compressive strength of different amount of coal gangue in cement mortar

\begin{tabular}{ccccccccc}
\hline Coal gangue content $(\%)$ & 0 & 15 & 30 & 50 & 70 & 90 & 110 \\
\hline $3 \mathrm{~d}(\mathrm{Mpa})$ & 10.53 & 8.62 & 7.39 & 6.96 & 5.69 & 5.35 & 0.63 \\
$7 \mathrm{~d}(\mathrm{Mpa})$ & 15.21 & 16.87 & 15.92 & 9.46 & 6.94 & 7.5 & 4.28 \\
$28 \mathrm{~d}(\mathrm{Mpa})$ & 25.42 & 24.56 & 23.31 & 21.15 & 16.39 & 13.04 & 12.27 \\
\hline
\end{tabular}

The coal gangue cement samples with different amount of flexural strength is shown in Table 3 , from the data in the table can be seen, with the addition of calcined coal gangue increases, sample pre bending strength is not reduced, but there is increasing trend. When the amount of coal gangue was $50 \%$, the flexural strength reached the maximum at 28 days, and the maximum value was 7.12MPa. When the coal gangue amount of more than $70 \%$, the flexural strength of cement mortar with coal gangue decreases rapidly and the added amount of $110 \%$ samples, the flexural strength of 3 days is almost zero, was the 28 day flexural strength is very low, only $4.75 \mathrm{MPa}$. Cement mortar mechanical properties test results of comprehensive comparison of different content of coal gangue, coal gangue when the calcination temperature is $600^{\circ} \mathrm{C}$ in the premise of not greatly reducing the compressive and flexural strength of cement mortar, the amount of coal gangue is the optimal doping amount of $50 \%$.

Table. 3 Flexural strength of different amount of gangue in cement mortar

\begin{tabular}{cccccccc}
\hline Coal gangue content $(\%)$ & 0 & 15 & 30 & 50 & 70 & 90 & 110 \\
\hline $3 \mathrm{~d}(\mathrm{Mpa})$ & 1.76 & 2.31 & 1.96 & 2.17 & 1.94 & 2.00 & - \\
$7 \mathrm{~d}(\mathrm{Mpa})$ & 3.45 & 3.56 & 3.61 & 3.80 & 2.95 & 3.38 & 2.62 \\
$28 \mathrm{~d}(\mathrm{Mpa})$ & 5.87 & 6.12 & 6.75 & 7.12 & 6.56 & 5.20 & 4.75 \\
\hline
\end{tabular}

The effect of mechanical properties of coal gangue cements mortar with different $\mathrm{Na}_{2} \mathrm{SO}_{4}$ content. Under the condition that the amount of calcined coal gangue is $50 \%$, the influence of $\mathrm{Na}_{2} \mathrm{SO}_{4}$ as an activator on the mechanical properties of cement mortar is investigated. The amount of activator $\mathrm{Na}_{2} \mathrm{SO}_{4}$ is the mass percentage of the added gangue, and the experimental results are shown in Table 4 and table 5. As can be seen from table 4, when the activation agent $\mathrm{Na}_{2} \mathrm{SO}_{4}$ is below $6 \%$, the compressive strength of the specimens increases significantly, and the strength of the latter 28 days increases slightly. When $\mathrm{Na}_{2} \mathrm{SO}_{4}$ is $3 \%$, the strength of the sample reaches the maximum at 28 days, and the maximum is $23.59 \mathrm{MPa}$. When the adding amount of $\mathrm{Na}_{2} \mathrm{SO}_{4}$ is more than $6 \%$, the compressive strength of both the early and late samples decreased.

Table 5 is the effect of the amount of activator $\mathrm{Na}_{2} \mathrm{SO}_{4}$ on the flexural strength of cement mortar. It can be seen from the table that the addition of activator $\mathrm{Na}_{2} \mathrm{SO}_{4}$ can weaken the flexural strength of cement mortar. When the addition amount is less than $6 \%$, the flexural strength of specimens decreases, but the decrease is not great. When the dosage of activator is more than $6 \%$, the flexural strength of specimens decreases greatly compared with that without activator $\mathrm{Na}_{2} \mathrm{SO}_{4}$. Comprehensive experimental results show that the amount of activator $\mathrm{Na}_{2} \mathrm{SO}_{4}$ should be no more 
than $6 \%$, and adding $3 \%$ is most appropriate.

Table 4. Effect of activator Na2SO4 addition on compressive strength of cement mortar

\begin{tabular}{cccccc}
\hline $\mathrm{Na}_{2} \mathrm{SO}_{4}$ concent $(\%)$ & 0 & 3 & 6 & 9 & 12 \\
\hline $3 \mathrm{~d}(\mathrm{Mpa})$ & 6.96 & 11.23 & 8.51 & 6.12 & 5.17 \\
$7 \mathrm{~d}(\mathrm{Mpa})$ & 9.46 & 14.54 & 12.54 & 7.92 & 8.49 \\
$28 \mathrm{~d}(\mathrm{Mpa})$ & 21.15 & 23.59 & 21.37 & 17.52 & 13.58
\end{tabular}

Table 5. Effect of the amount of activator Na2SO4 on flexural strength of cement mortar

\begin{tabular}{cccccc}
\hline $\mathrm{Na}_{2} \mathrm{SO}_{4}$ concent $(\%)$ & 0 & 3 & 6 & 9 & 12 \\
\hline $3 \mathrm{~d}(\mathrm{Mpa})$ & 2.17 & 2.46 & 2.09 & 1.82 & 1.71 \\
$7 \mathrm{~d}(\mathrm{Mpa})$ & 3.80 & 3.42 & 2.49 & 2.37 & 2.02 \\
$28 \mathrm{~d}(\mathrm{Mpa})$ & 7.12 & 5.48 & 5.25 & 5.32 & 5.31 \\
\hline
\end{tabular}

\section{Conclusions}

The coal gangue in Liupanshui area has the lower content of quartz and the waste washing sediment. It can be used as the admixture of cement cementing material at the calcination temperature of 600 degrees and the holding time of $2 \mathrm{~h}$. The amount of coal gangue has little influence on the mechanical properties of cement mortar. When the addition amount is more than $70 \%$, the compressive strength of cement mortar will be reduced remarkably. The optimum amount of coal gangue is $50 \%$, and its compressive strength can reach $23.31 \mathrm{MPa}$ in 28 days. The addition of chemical activator $\mathrm{Na}_{2} \mathrm{SO}_{4}$ can improve the compressive strength of cement mortar due to its activation and activation of coal gangue, but it can weaken the flexural strength of specimens. The optimum addition amount of $\mathrm{Na}_{2} \mathrm{SO}_{4}$ is $3 \%$. At this time, the strength of specimens is 3 days, and the compressive strength of 28 days is $23.59 \mathrm{MPa}$, 11.23MPa.

\section{Acknowledgements}

This study has been supported by the Guizhou provincial science and technology department joint fundation (Qiankehe Jzi LKLS [2013]19); Guizhou province ordinary college innovation team of mineral processing and comprehensive utilization of scientific and technological (Qianjiaohe Talent team zi[2015] 69); Guizhou provincial department of education fund project (QianjiaoheKYzi[2016]102); Guizhou province ordinary college innovation team of coal solid waste recycling technology (Qianjiaohe Talent team zi [2014]46).

\section{References}

[1] X.M.Duan,J.W.Xia,J.P.Yang: Jianzhu Cailiao Xuebao Vol.17 (2014),P.700-705.

[2] Wen Xia Li,Dong Li Wang,Ji Shou Niu,et al. Advanced Materials Research Vol.2339 (2013), P.159-162.

[3] Li Li Hu. Materials Science Forum Vol.4269 (2016),P.96-104.

[4] Deshun Kong,Zhi Li,Jiaxin Fan et al: Coal Engineering Vol.7(2013),P.99-101. In Chinese.

[5] Xiujun Guo: Coal engineering Vol.49(2016),P.74-76. In Chinese.

[6] Hu Zhu Zhang, Yuan Fang. Applied Mechanics and Materials Vol.3489 (2014),P.1536-1540. 